Table 1. Mean consumer ratings of three attributes for three media with Dallas fern during 6 weeks of in-home evaluations.

\title{
Consumers Evaluate a Growing Medium Containing Broiler Litter Compost
}

\author{
Bridget K. Behe ${ }^{1}$, Lillie V. Purvis ${ }^{2}$, Lisa M. Beckett ${ }^{3}$, \\ Charles H. Gilliam ${ }^{4}$, and James O. Donald ${ }^{5}$ \\ Department of Horticulture, College of Agriculture, Auburn University, \\ AL. $36849-5408$
}

Additional index words. poultry, litter, compost, fern

\begin{tabular}{lccc}
\hline & \multicolumn{3}{c}{ Mean rating of attribute } \\
\cline { 2 - 4 } Medium & Color $^{\mathrm{y}}$ & Health $^{\mathrm{x}}$ & Odor $^{\mathrm{w}}$ \\
\hline Baccto & $3.7 \mathrm{a}$ & $3.7 \mathrm{a}$ & $1.1 \mathrm{a}$ \\
Hyponex & $3.0 \mathrm{~b}$ & $3.1 \mathrm{~b}$ & $1.1 \mathrm{a}$ \\
AUmix & $3.6 \mathrm{a}$ & $3.6 \mathrm{a}$ & $1.2 \mathrm{~b}$
\end{tabular}

${ }^{2}$ Data did not violate analysis of variance assumptions and were analyzed using Duncan's multiple range test, $P \leq 0.05$.

${ }^{y}$ Fern frond color was rated from $1=$ light green to $5=$ dark green.

${ }^{x}$ Fern health was rated from $1=$ fair health to $5=$ excellent health.

"Medium unpleasant odor was rated from $1=$ no

unpleasant odor to $5=$ strong unpleasant odor.

Chicken litter compost can be substituted for peatmoss in growing media (Bugbee and Frink, 1989). We hypothesized that consumers' perception of an objectionable odor may limit marketability of litter compost in horticultural products. The objective of this study was to determine consumer acceptance of a growing medium amended with litter compost. We conducted the study in consumer homes to provide a realistic setting and compared our growing medium containing litter compost (AUmix) with two commercial alternatives-Baccto (Michigan Peat Co., Houston) and Hyponex (Hyponex Co., Marysville, Ohio). We hypothesized that performance similar to at least one commercial alternative for three of four product attributes would indicate acceptability. AUmix contained (by volume) 10 broiler litter compost : 10 aged, amendmentgrade pine bark : 1 horticultural-grade perlite.

Received for publication 10 June 1992. Accepted for publication 29 Dec. 1992. Alabama Agricultural Experiment Station no. 11-923236. Mention of a trademark, proprietary product, or vendor does not imply endorsement by Auburn Univ., nor criticism of similar ones not mentioned. We thank the Alabama Univ. Tennessee Valley Research Consortium for its generous funding of this project. The cost of publishing this paper was defrayed in part by the payment of page charges. Under postal regulations, this paper therefore must be hereby marked advertisement solely to indicate this fact.

${ }^{1}$ Assistant Professor of Horticulture.

${ }^{2}$ Former Graduate Student,

${ }^{3}$ Research Technician.

${ }^{4}$ Professor of Horticulture.

${ }^{5}$ Professor of Agricultural Engineering, Dept. of Agricultural Engineering.
On 17 Oct. 1990, we transplanted commercially grown $2.5-\mathrm{cm}$ Dallas fern [Nephrolepsis exaltata (L.) Schott] 'Dallas Jewel' liners one each into 450-ml plastic containers with one of the media and grew the ferns for 1 week in a fiberglass-covered greenhouse. Of $\approx 300$ members of 23 garden and homemaker clubs in Lee Co., Ala., contacted, 119 agreed to participate. Participants were told that the purpose of the study was to evaluate a new potting mix. They were not told that one medium contained broiler litter compost. Results from a survey mailed to participants at the study's conclusion showed that percentages of respondents (67 of 112) by age were $28 \%, 33$ to $50 ; 34 \%, 51$ to 66 ; and $37 \%, 67$ to 85 . Eighty-seven percent of the respondents had completed some college or earned a college degree. Mean per capita income was $\$ 21,502$. The mean number of persons per household was 2.5 : $88 \%$ of the respondents was female and $12 \%$ male.

Between 24 Oct. and 1 Nov. 1990, consumers randomly chose a set of three ferns. Participants received an instruction sheet, six color-coded forms for weekly evaluations, and six postage-paid envelopes. Containers were labeled A, B, or C, and medium order varied randomly in each fern set. Care instructions were provided on commercially produced tags.

From 2 Nov. through 7 Dec., consumers evaluated each fern on four variables, comparing the plant being rated to the other two plants. Ninety-four percent of the consumers completed the study. Data were ranked and did not violate analysis of variance assumptions. Consumer mean ratings were compared using Duncan's multiple range test. Week $\times$ treat- ment interactions were not significant for plant color and health and medium odor.

Ferns grown in Hyponex were perceived to be a lighter green when compared to plants in AUmix and Baccto, which were similar in mean color ratings (Table 1). Ferns in Hyponex were perceived as less healthy than those in AUmix or Baccto, which received similar mean health ratings. During the 6-week evaluation, ferns in Hyponex were rated $(1=$ little, $5=$ considerable) as requiring the most water (rating 3.3), Baccto the least (rating 2.4), and AUmix an intermediate amount (rating 2.7). All ratings differed at $P \leq 0.05$.

Whether the participants would perceive an unpleasant odor was our primary concern. Consumers noticed minimal unpleasant odor from Baccto and Hyponex, slightly less than that noticed from AUmix (Table 1). AUmix received a rating of 2 or higher by no more than $13 \%$ of the participants during the 6 weeks of evaluation. Since few participants noticed any unpleasant odor and only a minimal amount was detected, we conclude that AUmix odor perceptions likely will not limit its marketability. Ferns in AUmix received higher ratings than ferns in one commercial medium and ratings similar to those in the other medium for the three other factors evaluated in this study. From these results, we conclude that a growing medium amended with broiler litter compost could be acceptable for use in consumer homes.

\section{Literature Cited}

Bugbee, G.J. and C.R. Frink. 1989. Composted waste as a peat substitute in peat-lite media. HortScience 24:625-627. 